\title{
Circumstantial and Temporal Dependence in Counterfactual Modals
}

\author{
Dorit Abusch \\ Cornell University
}

\begin{abstract}
Counterfactual" readings of might/could have were previously analyzed using metaphysical modal bases. This paper presents examples and scenarios where the assumptions of such a branching-time semantics are not met, because there are facts at the base world that exclude the complement of the modal becoming true. Additional arguments show that counterfactual readings are context-dependent. These data motivate a semantics using a circumstantial (or factual) modal base, which refers to context-dependent facts about a world and time. The analysis is formulated in a version of the premise semantics for modality.
\end{abstract}

Keywords: metaphysical modality, circumstantial modality, premise semantics, interactions between tense and modality, branching time, natural language semantics.

\section{Introduction}

Sentences like (1) and (2) have readings which seem to describe unrealized past possibilities: at the mentioned time, it was possible for him to win, but this possibility was not realized. At some past time, it was possible for Ljubojević to become world champion in 1978, but that possibility was not realized. Such readings of might have and could have are called counterfactual readings in this paper. The same verb complexes have epistemic readings, describing epistemic uncertainty at the present time about a situation in the past. Thus (2) can describe the speaker's uncertainty at a speech time about whether Ljubojević was world champion in 1978 or not. Such epistemic readings are not the topic of this paper.

(1) At that time, he might still have won the game but he didn't in the end.

(Condoravdi 2002).

(2) Ljubojević might have been the world champion of chess in 1978. Mondadori (1978).

Mondadori (1978) and Condoravdi (2002) proposed a semantic analysis of counterfactual readings using branching world-time models. These passages from Mondadori's and Condoravdi's papers describe the idea succinctly.

Consequently, the reason that "might" is indexed to the future must be sought elsewhere. I suggest that it can be found in the circumstance that "might" is generally associated with a picture of time as "branching". Thus when I claim that Ljubojević might be the world champion in chess in 1978, it is (now) "open" to him to go on and become the next world champion in chess. (Mondadori 1978) 
The counterfactual reading involves a future possibility in the past and the modality is metaphysical. [1] is used to communicate that we are now located in a world whose past included the (unactualized) possibility of his winning the game. The possibility is about how the world might have turned out to be: at some point in the past the world was such that it could evolve into a world in which he won the game. At the relevant point in the past, the issue whether he won or not had not been settled and the world could have developed in either way.

(Condoravdi 2002)

In a branching model construction, the possibility of the base world $w_{0}$ at a time $t$ evolving into a world in which he wins the game is explicated using branching: there must be a world $w$ in which he wins after time $t$, and which branches from $w_{0}$ at a time no earlier than $\mathrm{t}$.

In her compositional analysis, Condoravdi proposed that for "he might have won" to be true, the clause "he might win" has to be true in the past. This is achieved by an LF where "have" has scope over the modal as shown in the syntactic representation (3)b for (3)a. ${ }^{1}$ The order of the operators is as follows: first present tense, then might, then the atomic sentence he win. (3)c gives some of Condoravdi's morpheme meanings and related definitions. The morphemes combine by function application to produce the semantics (3)d for (3)b. The formula requires that there is a time $t$ such that $t$ precedes the utterance time $n$, and there is a world $w$ which is a "metaphysical" alternative to the base world $w_{0}$ at the past time $t$, and an event $e$, which is an event of John winning in $w$, and whose temporal projection $\tau(e, w)$ in $w$ is included in the unbounded interval $[t, \infty)$ running from $t$ to positive infinity.

(3) a. John might have won.

b. Pres [have [might [ he win ]]]

c. [have $\rrbracket=\lambda P \lambda w \lambda t \exists t^{\prime}\left[t^{\prime}<t \wedge \operatorname{AT}\left(t^{\prime}, w, P\right)\right]$ 【might $\rrbracket=\lambda P \lambda w \lambda t \exists w^{\prime}\left[\mathrm{M}(w, t)\left(w^{\prime}\right) \wedge \operatorname{AT}\left([t, \infty), w^{\prime}, \mathrm{P}\right)\right]$

$$
\begin{aligned}
\operatorname{AT}(t, w, P) & =\exists e[P(w)(e) \wedge \tau(e, w) \subseteq t] & & P \text { eventive } \\
& =\exists e[P(w)(e) \wedge \tau(e, w) \circ t] & & P \text { stative } \\
& =P(w)(t) & & P \text { temporal }
\end{aligned}
$$

d. $\exists t\left[t<n \wedge \exists w\left[\mathrm{M}\left(w_{0}, t\right)(w) \wedge \exists e[\tau(e, w) \subseteq[t, \infty) \wedge \mathbf{w i n}(w, e, \mathbf{j o h n})]\right]\right]$

There are a couple of things to note about the meaning of might. First, it is an existential quantifier over worlds, and the domain of quantification is a modal base $\mathrm{M}\left(w_{0}, t\right)$. Stating the semantics in this way is equivalent to using an accessibility relation. An important point is that the accessibility relation varies with times in addition to worlds. So, fixing $w_{0}$ and $t, \mathrm{M}\left(w_{0}, t\right)$ is the set of accessible worlds, and in formula (3) $\mathrm{d} w$ is an element of this set, that is $w$ is accessible from $w_{0}, t$. Second, the modal builds in futurity in the requirement that the event $e$ falls in the unbounded interval $[t, \infty)$, so that the event time for the winning event $e$ is no earlier than $t .^{2}$ Finally, there is the idea that 
the modal base in such sentences consists of "metaphysical" alternatives. This was suggested by Mondadori, and Condoravdi built it into a compositional semantics. Metaphysical alternatives are a certain way of formalizing branching of worlds. A metaphysical alternative to $w_{0}$ at $t$ is a world $w$ which is the same as $w$ up to and including $t$. This requirement is agnostic as to whether the worlds $w_{0}$ and $w$ literally overlap up to and including $t$, or whether they are merely qualitatively the same up to $t$. In either case, any difference between $w$ and $w_{0}$ must come after $t$, and one can think of $w$ as branching off from $w_{0}$ after $t^{3}$

(4)b gives a picture of Condoravdi's analysis of (4)a. In a model where the sentence is true at $w_{0}$ and $n$, there is a time $t_{1}$ which precedes $n$, and a world $w$ which is a metaphysical alternative to $w_{0}$ at $t_{1}$. In the alternative world $w$, there is required to be an event $e$ of John winning, which is temporally included in the interval $\left[t_{1}, \infty\right)$. Informally, $w$ is a branch from $w_{0}$ after $t_{1}$ where John later wins.

(4) a. At that time, he might/could still have won the game

b.

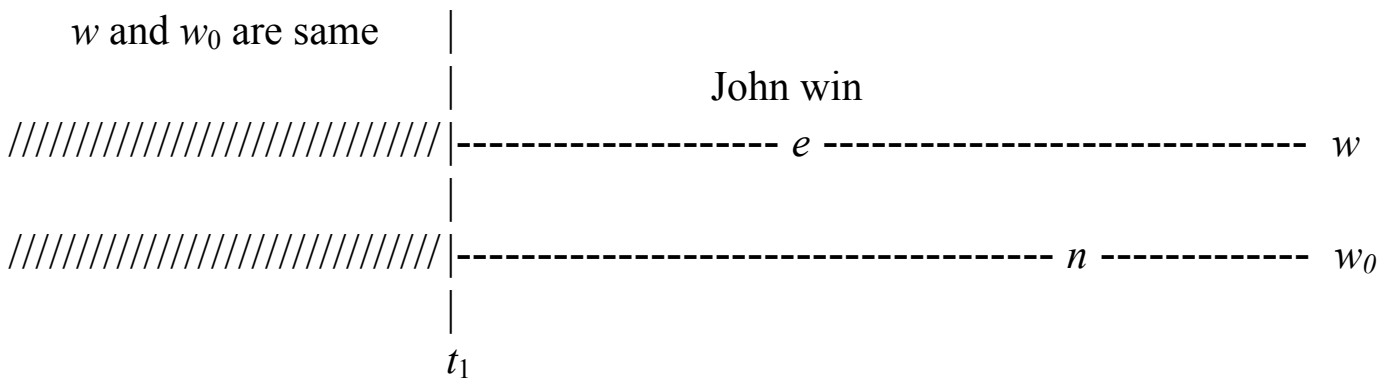

\section{Problems with the branching-time analysis}

It should be emphasized that the analysis using metaphysical alternatives must be taken literally. This means that the base world and the alternative need to be exactly the same up to the time of evaluation of the modal. I am going to give some examples and scenarios which are problematic for this aspect of the metaphysical analysis. The first one is the trees scenario given in (5). The husband's statement includes typical counterfactual uses of might have, which describe past possibilities which were not realized. In response, the wife made an argument to an opposite conclusion, given in (6). This is the kind of argument one makes just to win an argument, but it seems valid up to the last sentence.

(5) The trees

There were two huge beautiful old trees in my front yard. In a summer storm, one of them was blown down. Fortunately, it fell away from the house onto the driveway, rather than towards the house onto my husband's office. When we looked at the broken trunk, we saw that it was rotted inside, so this was a dangerous tree. The trees were of similar appearance and age. 
Husband's argument: I might have been killed, because the tree might have fallen onto my office. Let's cut down the other tree. It might fall onto my office in another storm.

(6) Wife's Argument: We bought the house for the trees, and now you want to cut them down? Anyway the tree guy told us that because of the location of the rot in the trunk, the tree could only fall away from the house. So the tree could not have fallen onto your office. There is no reason to cut down the other tree.

Sentence (7)a is from the husband's argument, and (7)b is from the wife's argument. The relevant reading in (7)b is one where the negation scopes over the modal, so that the wife's sentence has the syntactic form of a negation of the husband's sentence. ${ }^{4}$ Intuitively, one feels that the sentences are superficially contradictory, but that nevertheless one can understand each of them as true.

a. Husband: The tree might/could have fallen on my office.

b. Wife: The tree could not have fallen on your office.

Here is the problem for the metaphysical analysis. If the two sentences are to be evaluated with respect to a single base world, then that world determines a unique set of metaphysical alternatives. So we can not get both of them to be true on a metaphysical reading. A common strategy for resolving this kind of problem is to identify a shift in an implicit parameter between the two utterances, so that taking into account the contextual parameters, (7)a and (7)b are not contradictory. It is not clear what this parameter could be in the branching time analysis. Perhaps one could try to say that the husband and wife are referring to different worlds, which branch in different ways. But it seems that the husband and wife intend to refer to the same real situation, and do not disagree about any matter of fact. Rather, as I will claim, the wife makes a modal argument which pays attention to the specific location of rot in the first tree, while the husband makes a modal argument which pays attention to the fact that the tree has internal rot, but considers the specific location of the rot (on the driveway side of the tree) a factor which is to be ignored, because he wishes to draw a modal conclusion about the other tree.

The next group of examples involves a special modality which I call sports math modality, which is used by sports announcers, writers, and fans. (8)a is an example with the verbal complex could have, and (8)b is a synonymous nominal example. Sports math modality is signaled by the adverb mathematically, and by similar ones such as technically. Temporal adverbs which constrain the temporal argument of the modal fit in easily, since when sports math sentences are used, there is usually an intention to talk about how possibilities evolve and are gradually foreclosed as time passes.

(8) a. In week 11 of the football season, mathematically, Buffalo could still have reached the playoffs.

b. In week 11 there was still a mathematical possibility of Buffalo reaching the playoffs.

Sports modality has a very specific semantics. In evaluating sentences like these, one pays attention only to the history of play in $w_{0}$ up to the reference time $t_{1}$, the league 
schedule in $w_{0}$, and league regulations in $w_{0}$. Other facts about $\mathrm{w}_{0}$ are stipulated to be irrelevant. Suppose for instance that in week 11, all of the Buffalo players had broken legs, so that it was impossible for Buffolo to win any more games. Or suppose that the officials had been bribed to give advantage to the opponents. Facts such as these are irrelevant to assessing truth in (8) and the sentences can still be true even if there are certain facts $F$ about $w_{0}$ at $t_{1}$ which absolutely exclude the possibility of Buffolo winning any more games, and if winning some more games is essential to Buffalo qualifying.

The problem for the metaphysical analysis is that, since metaphysical alternatives are exactly the same as the base world up to the reference time, the elements of $F$ are also facts about the alternatives---the Buffalo players also have broken legs in the alternatives. So Buffalo will not reach the playoffs in the metaphysical alternatives either, so that the sentences are false if a metaphysical modal base is used in evaluating the modal. Intuitively of course, the sentences can be true.

Here is another example that makes the same point. I want to imagine a tournament which involves people and computer chess programs. The computer chess programs play deterministically, so that once you set them up, it is determined how they are going to play. If you set up two computer chess programs repeatedly in the same way to play with each other, they would play the same game again and again. Now consider a tournament involving Ljubojević and two computer chess programs, Shredder 9 and Shredder 10. We stipulate that because of the algorithms implemented in those systems, in their deterministic play with the given initial conditions Shredder 10 defeats Shredder 9. On Nov. 15, the tournament reached a stage where it was in the sports-math sense possible for Ljubojević to reach the quarterfinals. But because of the particular pattern of results so far, that would have required Shredder 9 defeating Shredder 10. And that is impossible because of the algorithms implemented in those systems. Under these circumstances, sentence (9) can still be judged as true in a sports math sense.

(9) On Nov. 15, mathematically, Ljubojević could have reached the quarterfinals.

We are stipulating that if we set up the situation this way it is not possible for Shredder 9 to defeat Shredder 10. Therefore, on Nov. 15, there is no metaphysical alternative where Shredder 9 defeats Shredder 10, and therefore, there is no metaphysical alternative where Ljubojević reaches the quarterfinals. But somehow, in evaluating the modal sentence understood in a sports-math sense, we can reason as if a defeat of Shredder 10 by Shredder 9 is possible. Apparently, this requires considering alternatives which are not metaphysical alternatives.

If the modal base in these examples is not metaphysical, what is it? One possibility in the tree example is a doxastic or epistemic modal base. Before the first tree fell, the husband would have assented to the conditional sentence (10)a. In doing so, he takes advantage of his information about the geometric and physical configuration of the tree and house, and how trees move in storms. In these circumstances, the belief sentence (10)b is also true. Since the semantics for belief sentences involves quantification over doxastic alternatives, this makes it plausible that (7)a in the tree scenario might also involve quantification over doxastic alternatives. Perhaps, when implicit parameters are filled in, it amounts to something like (11). 
(10) a. If the tree falls, it might fall onto the office.

b. At that time, the husband believed that if the tree fell, it might fall on the office.

(11) In view of what the husband knew about the property at the time of the storm, when the tree fell, it might have fallen on the office.

Doxastic and epistemic modalities are modalities that use the doxastic (or epistemic) state of an agent to determine a set of worlds that serves as the domain of quantification for the modal. We can eliminate this option by taking away the agents. Here is a revised scenario.

(12) The Trees and orchids

The two trees are in a part of the couple's forest reserve which at the time of the storm nobody had ever visited. The tree fell away from a growth of endangered orchids. The couple find it several months after it fell. The husband makes the argument (13)a. The wife (caring more about trees than flowers) counters with (13)b. The facts about the rot are as before.

(13) a. The tree could have fallen on the orchids. Let's cut down the other tree. It might fall on the orchids in another storm.

b. The tree could not have fallen on the orchids, because the rot was on the other side.

The point about that part of the reserve never having been visited until months after the storm is that at the time of the storm, there was no agent who had information about the trees. Nobody had ever seen those trees, and no person (or robot, or other agent with an epistemic state) had information about them. So the modality in (13) could not be doxastic or epistemic, in the sense of using the information of an agent at a time to determine a domain of quantification.

Pragmatically, there is arguably an epistemic or doxastic modality layered above the modality in (13), because one can draw conclusions about the speakers' beliefs at the utterance time. But this is something entirely systematic, which is true also about nonmodal sentences. Doxastic modality can be made overt as in (14). This sentence has one reading where the modality of could merges with the belief modality. ${ }^{5}$ This reading does not fit with the scenario, because at the time of his statement, the husband knows that the tree fell away from the orchids. The reading that fits into the context has the order or operators believe $>$ have $>$ could, and is a counterfactual reading of the kind being discussed here. As argued above, in this scenario and with this order of operators, the could-modality is not epistemic or doxastic: the sentence does not describe the husband's beliefs about the information of an agent (either himself or someone else) at the past time.

(14) The husband believes the tree could have fallen on the orchids.

Above, I noted that judgments of truth in the tree example shifted, depending on what information about the trees one pays attention to. The following completely invented scenario about the Yugoslav and Soviet grand masters brings out the variability. Ljubojević lost the title match to Karpov in 1977. When he worked on strategies throughout the 1970s, he explored strategies which Karpov was also examining. Since Karpov was in important respects more capable, Ljubojević lost. But later analysis showed that if he had started working in 1975 on the strategy which later became known 
as the Mexican Defense (and which Ljubojević became a master of), he might well have beaten Karpov. In this context, the sentences in (15) are judged true. We can justify this by pointing out that if Ljubojević had started working on the Mexican defense earlier, he might well have won.

\section{(15) True In 1975, Ljubojević might still have won.}

True In 1975, Ljubojević could still have won.

Now let's add some information: Ljubojević settled on his strategies (the ones that Karpov also examined) in the early 1970s. In those days he was a very methodical person who never made changes in strategy. Now the truth value seems to switch. The sentences repeated in (16) seem false because in 1975, he had already selected his strategies, and Ljubojević never changes strategy.

False (?)

In 1975, Ljubojević might still have won.

False (?)

In 1975, Ljubojević could still have won.

False, because although if he had started working on the Mexican defense, he might well have won, Ljubojević never changes strategy.

Comparing results for the two contexts shows that a shift in the context can change the truth value of the might have sentence. When the context does not bring up that Ljubojević never changes strategy, the sentence seems true. When the context does bring up that Ljubojević never changes strategy, the sentence seems false, though the intuition is a volatile one. How would this be captured in the branching-time analysis? A world branches in just one way, and it is not clear how the effect of context could be built into the analysis.

What is going on with (15) and (16) is intuitively pretty clear: the truth value shifts according to whether or not one "pays attention" to the fact that Ljubojević never changes strategy. ${ }^{6}$ The tree scenario also involved a shift in assumptions: the wife's argument paid attention to the particular location of the rot, while the husband's argument ignored it. The analysis developed below represents this intuition in a direct way.

What is the impact of the hypothesis that "anything is possible" on these claimed counterexamples to the metaphysical analysis of counterfactual modals? Despite the location of the rot on the opposite side of the trunk, maybe a mighty freak gust of wind could knock the tree onto the orchids. Maybe the players on the other teams could all break their legs too, neutralizing Buffalo's disadvantage. Maybe the computer on which Shredder 10 is running could be afflicted by a rare failure in its circuits, which results in behavior that is contrary to the Shredder 10 algorithm. Many would consider these things in principle possible. If we are working with branching time models, we should not dismiss the option that worlds where these odd things happen are genuine metaphysical alternatives. At an extreme, we can assume a space of worlds and times where combining an initial temporal half of one world-time line with a final temporal half of another results in another world, where everything has changed instantaneously. This would make almost anything metaphysically possible in any world at any time. While models of this kind are a theoretical option that is worth investigating, I think we should also look for an analysis that will work with models where all worlds are continuous and 
naturalistic. Anyway, models where anything is metaphysically possible have bad consequences for the metaphysical analysis of counterfactual modals. In such models typical sentences with top-level metaphysical modals are true, and sentences with negated metaphysical modals are false. Since Mondadori and Condoravdi did not consider the sentences they were analyzing trivial, "anything is possible" branching-time models are not a match for their theory. ${ }^{7}$

Before proceeding to an analysis, let us look at a less empirical objection to the analysis with metaphysical modal bases. Suppose all the worlds in the model have a determinist physics: given a complete description of $w_{0}$ at $t$, what happens in $w_{0}$ after $t$ is determined. Then the metaphysical alternative set for $w_{0}$ at $t_{1}$ is $\left\{w_{0}\right\}$, or a set of copies of $w_{0}$. By copy of $w_{0}$, I mean a world that is exactly like $w_{0}$ throughout time. In a model like this, metaphysical modals have no semantic effect. Here is why. In such a model, in the formula (17)b, which is the semantics of (17)a assuming that at that time designates $t$, the existential quantifier ranges over worlds $w$ which are copies of $w_{0}$ throughout time. Since $w$ is a copy of $w_{0}$, the formula win( $\left.w, e, \mathbf{j o h n}\right)$ is true if and only if win( $\left(w_{0}, e, \mathbf{j o h n}\right)$ is true. The same goes for the formula $\exists e[\tau(e, w) \subseteq[t, \infty)]$. Therefore, in a deterministic model, (17)b is true if and only if (17)c is. Using the fact that $w_{0}$ is a metaphysical alternative to itself, one can show by predicate-logical reasoning that (17)c is equivalent to $(17) \mathrm{d}$, where the world quantifier has been eliminated, and only the temporal part of the meaning of might remains. So, in a deterministic model, metaphysical might is equivalent to will, clearly a bad result.

a. At that time, John might have won.

b. $\exists w\left[\mathrm{M}\left(w_{0}, t\right)(w) \wedge \exists e[\tau(e, w) \subseteq[t, \infty) \wedge \mathbf{w i n}(w, e, \mathbf{j o h n})]\right]$

c. $\exists w\left[\mathrm{M}\left(w_{0}, t\right)(w) \wedge \exists e\left[\tau\left(e, w_{0}\right) \subseteq[t, \infty) \wedge \mathbf{w i n}\left(w_{0}, e, \mathbf{j o h n}\right)\right]\right]$

d. $\left.\exists e\left[\tau\left(e, w_{0}\right) \subseteq[t, \infty) \wedge \operatorname{win}\left(w_{0}, e, \mathbf{j o h n}\right)\right]\right]$

There are two reactions to this observation. First, in the spirit of Bach (1986), we could accept that the grammar and semantics of English have metaphysical presuppositions which happen to be inconsistent with certain metaphysical options. This is a curious result of natural language semantics, not any kind of problem. My reaction is different. I'd like to have a theory of semantics which is compatible with a range of physical and metaphysical assumptions. Independent of the empirical arguments above, this makes me suspicious about the Mondadori-Condoravdi analysis. I can't prove it, but my position is that if speakers assumed all possible worlds are deterministic, they would use counterfactual modals in exactly the way that they do. ${ }^{8}$

My conclusion from the office/orchid, sports-math, and chess match examples is this. There are scenarios and examples which in their syntactic and semantic properties (such as the specific syntactic and lexical forms that are involved, and the time-sensitivity of the modal claim) are like the examples Mondadori and Condadori wanted to analyze, but where the modal base can not be metaphysical, because there are facts about the base world at the reference time which exclude the truth of the complement of the modal. Given the definition of metaphysical modality, these are also facts about metaphysical alternatives, and so the complement of the modal is not true in the future in any 
metaphysical alternative. Thus counterfactual readings of might have and could have do not always exploit a metaphysical modal base.

\section{Circumstantial modality}

In all the scenarios and examples, there are some facts about the base world (the specific location of rot, the strategy that Ljubojevic has settled on together with the fact that he never changes strategy, the results of league play up to week 11) that allow or exclude the outcome described in the circumstantial modal sentence. I hypothesize that rather than being metaphysical or epistemic, the modal base in these examples is determined by such facts. That is, I will analyze the modality of might and could in these examples as circumstantial or factual modality. (18) is a variation on an example from Kratzer (1991) that illustrates the notion of circumstantial modality. We are looking at a region of an Earth-like planet through the lens of telescope, and observe an area with certain conditions (temperate climate, loamy soil, partial shade, morning and afternoon sun, etc.) One of us says (18). The statement can be paraphrased 'the circumstances of climate, soil, etc. there are consistent with the growth of Hydrangeas.' To judge the statement true, one must pay attention to these facts, but ignore some other ones, such as the fact that hydrangeas were never introduced on the planet, and that (let us stipulate) it is impossible for hydrangeas to get to the planet.

(18) Hydrangeas could grow there.

Kratzer called such readings of modals circumstantial readings. Although the hydrangea example has a certain generic flavor which is absent from the examples under discussion in this paper, the examples are in other ways similar, and this is the terminology I will apply. Kratzer proposed that the semantic analysis of such examples refers to sets of "relevant" facts or circumstances of the situation. These sets are called circumstantial modal bases or ordering sources. A fact about the world $w$ is a proposition that is true in $w$.

The same notion comes up in legal reasoning. Mr. Jones was accused of attempted indecent liberties with a child. After internet exchanges with Officer Mellard, who presented himself as a thirteen-year old female, he met in a shopping mall with Officer Arterburn, a young (but adult) policewoman, for the purpose of going elsewhere for sexual activity. He was arrested in the parking lot. In appeal, his lawyer argued that indecent liberties with a child were impossible, because the person in his company was an adult. In the excerpt (19) from the judgment of the Kansas Supreme Court the modality for the two occurrences of impossible is circumstantial---it asserts impossibility in virtue of a fact of the actual situation (Supreme Court of Kansas, 2001). The same works as a reading of could in the invented example (20). ${ }^{9}$

(19) Since Officer Mellard and Officer Arterburn are adults, appellant argues that it was legally or factually impossible for him to commit. He relies on the crime of attempted indecent liberties with a child. Spencer v. State, 264 Kan. 4, 954 P.2d 1088 (1998), in support of his contention that a crime can be nonexistent because it is legally or factually impossible to commit. 
(20) Mr. Jones could not have taken indecent liberties with a child, because the person in his company was an adult.

The notion of 'factual' possibility in this legal discussion appears to be identical to the 'circumstantial' modality discussed in semantics. The example is similar to the ones discussed here, in that it refers to concrete situation, and in that the possible events of taking indecent liberties temporally follow the events in the café and parking lot.

I will couch my analysis of circumstantial modals in the premise semantics of Veltman and Kratzer, specifically the semantics of modals found in Kratzer (1991). ${ }^{10}$ In the simplest version, a set of propositions $F$ that are all true in the base world are hypothesized as an implicit parameter of the modal. $F$ is called a circumstantial modal base. The domain of quantification for the modal is the set of worlds where each proposition in $F$ is true, i.e. the intersection of $F$ in the possible-worlds construction of propositions. (21) is the compositional structure of (18), with the modal having an implicit parameter $F$.

(21) [[could $F]$ [hydrangeas grow there]]

A basic property I want to exploit is that we get different truth values for circumstantial modal sentences by choosing different facts. Earlier, I said that the wife's argument in the tree example paid attention to the specific location of the rot (on the driveway side), while the husband's argument paid attention to the fact that there was rot of a certain extent, but ignored the specific location of that rot. The difference can be formalized by assuming that the modals in the wife's and husband's statements implicitly refer to different circumstantial modal bases. (22) is a partial description of the wife's facts. We assume that the husband's facts are the same, but with $p_{2}$, the fact which describes the specific location of the rot, replaced by a weaker proposition $q_{2}$.

Wife's facts in the Trees scenario $(F)$

$p_{1}$ There is a storm in our yard with such-and-such wind velocity.

$p_{2}$ The tree that fell has rot in such-and-such precise position within the trunk.

$p_{3}$ Facts about the top of the tree (how large it is, etc.)

$p_{4}$ Location of my husband's office relative to tree.

$p_{5}$ Physical or rule-of-thumb theory of tree motions under the influence of wind.

Husband's facts $(G)$

The same, with $p_{2}$ replaced by

$q_{2}$ The tree has such-and-such amount of rot within the trunk (without specifying location within the trunk).

Let $F$ be the set of facts (22), and let $G$ be the set of facts (23). The hypothesis is that the wife's modal implicitly refers to $F$, with the domain of quantification for the existential modal being $\cap F$, the set of all worlds in which each element of $F$ is true. The husband's modality implicitly refers to $G$, and his existential modal ranges over $\cap G$. Because of the difference between $F$ and $G, \cap F$ is a proper subset of $\cap G$ in any realistic 
model. This makes it possible for there to be a world $v$ where the tree falls on the office, and which is an element of $\cap G$, but not of $\cap F$. Suppose the husband's statement is formalized as in (24)a, and the wife's statement is formalized as in (24)b. If the modal expresses an existential world quantification ranging over the intersection of the modal base, the husband's sentence can be true with $v$ as a witness for the existential quantification, while the wife's sentence is also true, because its negation (24)c is false. Consequently the husband's and wife's statements, which in overt form appear contradictory, can both be true. Simply stated, the change from $F$ to $G$ allows there to be a world in the husband's domain of quantification but not the wife's domain of quantification where the tree falls on the office.

a. The tree [could $G$ ] have fallen on the office.

b. The tree [could $F]$ not have fallen on the office. (not $>$ could)

c. The tree [could $F$ ] have fallen on the office.

This captures the intuition that the husband's and wife's sentences, while superficially contradictory, are both true in their intended senses. The slyness in the wife's argument comes out as a shift in the implicit modal base. The shift is required if her sentence is to be true, but it makes her statement irrelevant as a counter to the husband.

The analysis so far does not provide for temporal and intensional variation in the modal base. The modal base in sports math consists of the results of play up to a certain time point. In (25), it is not sufficient to consider the results of play at one time; the results of play in both week and 11 and in week 12 are relevant, and must enter into the compositional semantics. So the modal base has to vary with the temporal compositional context.

(25) Mathematically, Buffalo could have reached the playoffs in week 11 but not week 12.

Similarly, consider sports-math modals embedded under believe. (26)a and (26)b convey information not about the actual results of play up to week 11, but about Mary's beliefs about the results of play up to week 11 . To model this, the modal base has to vary with Mary's doxastic alternatives. In each alternative, the modal base should consist of propositions describing the results of play in week 11 in that world.

(26) a. Mary believes that in week 11, there was a mathematical possibility of Buffalo reaching the playoffs.

b. Mary believes that mathematically, in week 11, Buffalo could have reached the playoffs

So the modal base parameter, rather than a constant set of propositions, should be a function mapping worlds and times to sets of propositions. For sports math, the right function maps a world and time to propositions describing the results of play in world $w$ up to time $t$. In (27), the set is described using a question, assuming the construction of a question denotation as a function from worlds and times to true atomic answers (Karttunen 1977). 
(27) Circumstantial sports math modal base function

$$
B_{\mathrm{sm}}=\lambda t \lambda w \llbracket \text { what NFL team plays what NFL team at what time preceding } t \text { in }
$$
regular-season play with what final score in $w \rrbracket^{w, t}$

One wants to set up the compositional semantics so that in (25), week 11 and week 12 , and not the utterance time, serve as the time arguments of the modal base function. In (26), the world and time arguments of the modal base function should be the world of a doxastic alternative for Mary and week 11 in that world. Before looking at a mechanism for this, let us take into account that the schedule of play for the entire season, and the league rules governing participation in the playoffs are also relevant in sports math modality. Suppose this information is represented with an additional function:

$O_{\operatorname{sm}}(t)(w)=$ set of propositions describing schedule of season play in $w$ at $t$, and league regulations in $w$ at $t$ determining participation in the playoffs.

The simplest move is to combine the two functions into a single premise function $\operatorname{Pr}_{\mathrm{sm}}$ by taking the union of the values, as defined in (29). We assume grammatical structures where an index $i$ is an argument of the modal, as in (30), and evaluate the logical form with respect to an assignment function $g$ such that $g(i)=\operatorname{Pr}_{\mathrm{sm}}$. Since what counts as a sports-math reading is captured by the premise function, this is a formalization of the sentence having a sports-math reading. The intensional and temporal interactions will then fall out as long as in the compositional derivation, the local world and time parameters get plugged in as the arguments of $g(i)$. In a standard intensional semantics, the same move is required in interpreting trace indices with an intensional type that are bound across an intensional context, such as the VP trace in (31). So it is sufficient to assume that the implicit argument of the modal has the status of a null pronoun with the type of the intension of an indirect question, as already established in the assumption that $g(i)=\operatorname{Pr}_{\mathrm{sm}}$. Then an independently motivated compositional mechanism ensures that the world and time arguments of the premise function are determined by the local compositional context. ${ }^{11}$

$$
\operatorname{Pr}_{\mathrm{sm}}=\lambda t \lambda w\left[B_{\mathrm{sm}}(t)(w) \cup O_{\mathrm{sm}}(t)(w)\right]
$$

(30) Mary believes [have [[in week 11] [[might 1] [Buffalo reach the playoffs ]]]]

(31) [[asleep] [2 [Mary believes John is $\left.\left.t_{2}\right]\right]$

Kratzer (1991) actually built two premise sets separately into the semantics of the modal, in order to deal with modals that have two dimensions of contextual dependence, and where one dimension may include contradictory constraints. In a scenario from that paper, legal judgments in New Zealand are governed by precedent. Two judges have given conflicting judgments about whether deer are financially responsible for damage to vegetation that they cause. Deer 432 has stripped the bark off a freshly planted young tree. If the case came to court, the judge could cite the precedent that holds deer responsible. So arguably (32)a is true, where as indicated by the "in view of" phrase, the modality is a deontic one capturing New Zealand case law. (32)b is also true, because a judge could cite the other precedent. ${ }^{12}$ 
(32) a. In view of what the New Zealand judgments provide, Deer 432 may be personally financially responsible for the costs of the damage to the sapling.

b. In view of what the New Zealand judgments provide, Deer 432 may not be personally financially responsible for the costs of the damage to the sapling. $($ may $>$ not $)$

We have these three pieces of information that contribute to a contradiction:

(33) $a$ Deer 432 has stripped the bark off the sapling.

$b$ Deer are financially responsible for damage to vegetation that they cause.

$c$ Deer are not financially responsible for damage to vegetation that they cause.

In the case law system, precedent $b$ can be followed and precedent $c$ ignored, or $c$ followed and $b$ ignored. Since precedent is to be followed as much as possible, it is not legitimate to ignore both $b$ and $c$. Ignoring $a$ would also resolve the contradiction, but case law is not applied to override facts. In the system proposed in Kratzer (1991), this reasoning is captured by putting $b$ and $c$ into an "ordering source" that is separate from the modal base that includes $a$. The ordering source encodes norms according to New Zealand case law. As a first approximation, an existential modal is true if there is some world where every proposition of the modal base is true, where every proposition in a maximal consistent subset of the ordering source is true, and where the complement of the modal is true. This allows contradictions in the ordering source to be resolved. ${ }^{13}$

In all the examples and scenarios in this paper, there are separate kinds of information that are relevant to the modality. In sports math, we have the results of play up to some time, and second, league regulations that determine participation in the playoffs. In the chess match scenarios, we have specific situations involving certain players, and the algorithms they were executing or the lines of play they were following. Second, there is the premise that Ljubjović never changes strategy, or that computers behave consistently with the programs they are running. In the tree scenario, we have first the configuration of the tree and the orchids at the time of the storm, and second something like a rule-ofthumb theory about how trees move.

The league regulations could be contradictory, just like New Zealand case law. That computers follow the programs they are running is a generalization that can be lifted in the presence of specific information about cosmic rays hitting a transistor in a certain way. That Ljubojević never changes strategy is presumably an "in the normal course of events" generalization that can also be lifted. It is easy to imagine rule-of-thumb physical theories being contradictory. So these premises belong in the ordering source. Furthermore, contradiction in the ordering source can be used to capture the indeterminacy that is part of the husband's view of things. The husband is assuming that when an externally symmetrical tree in our area falls in a storm, it can fall in any direction. This is captured with an ordering source that includes premises along these lines:

(34) $\quad q_{\mathrm{n}}$ If $x$ is an externally symmetrical tree that falls in a storm in our area, then $x$ falls in a northerly direction.

$q_{\mathrm{e}}$ If $x$ is an externally symmetrical tree that falls in a storm in our area, then $x$ falls in an easterly direction. 
$q_{\mathrm{s}}$ If $x$ is an externally symmetrical tree that falls in a storm in our area, then $x$ falls in a southerly direction.

$q_{\mathrm{w}}$ If $x$ is an externally symmetrical tree that falls in a storm in our area, then $x$ falls in a westerly direction.

We have in addition the facts partially listed in (35). Holding the facts constant, exactly one of the ordering propositions in (34) is true. This captures the husband's view that the tree could have fallen in any direction.

$p_{1}$ Tree DF4235 fell in Dryden, NY in Tropical Storm Lee at 17:03 on Sept. 8, 2011.

$p_{2}$ Orchid growth NYDEC87888 was three meters south of DF4235 at 17:03 Sept. 8,2011 .

At this point it has emerged that the modality in the tree-orchid example, which I previously described as a circumstantial modality, is better analyzed as a mixed circumstantial-physical modality, where the physical part is the rule-of-thumb theory of tree motion that the husband assumes. ${ }^{14}$

(36) is an official definition of the semantics of a future-oriented existential modal in the two-parameter theory. ${ }^{15}$ There are two modal parameters, a modal base $B$ and an ordering source $O$. Each is a set of propositions. Take a temporally sensitive proposition to have type $i w t$, where $i$ is the type label for times, and $w$ is the type label for world-time lines, and $t$ is the type label for truth values. Then a set of propositions has type $(i w t) t$. $B\left(t_{1}, w_{1}\right)$ as defined at the bottom means "every proposition in the modal base $B$ is true at time $t_{1}$ and world $w_{1}$ ". $\left\langle w_{1}, t_{1}\right\rangle \leq_{O}\left\langle w_{2}, t_{2}\right\rangle$ means " $\left\langle w_{1}, t_{1}\right\rangle$ is at least as optimal according to the ordering source $O$ as $\left\langle w_{2}, t_{2}\right\rangle$ ". The nested quantifications deal for one thing with the possibility of there being unbounded sequences of time-world pairs that are increasingly optimal according to the ordering source, so that (contrary to the approximate formulation stated earlier) there may not be a single time-world pair that witnesses the truth of the existential modal.

$$
\llbracket \text { might } \rrbracket^{g, t, w} \text { is the function } f \text { such that } f(B)(O)(p)=1 \text { iff }
$$

$$
\begin{aligned}
& \exists \mathrm{t}_{1} \exists w_{1}\left[B\left(\mathrm{t}_{1}, w_{1}\right) \wedge\right. \\
& \qquad \forall \mathrm{t}_{2}, \forall w_{2}\left[B\left(\mathrm{t}_{2}, w_{2}\right) \wedge\left\langle\mathrm{t}_{2}, w_{2}\right\rangle \leq O\left\langle\mathrm{t}_{1}, w_{1}\right\rangle \rightarrow\right. \\
& \left.\qquad \exists t_{3} \exists w_{3}\left[B\left(\mathrm{t}_{3}, w_{3}\right) \wedge\left\langle\mathrm{t}_{3}, w_{3}\right\rangle \leq O\left\langle\mathrm{t}_{2}, w_{2}\right\rangle \wedge \exists t_{4}\left[t_{3} \leq t_{4} \wedge p\left(\mathrm{t}_{3}\right)\left(w_{3}\right)\right]\right]\right] \\
& \text { where } B\left(\mathrm{t}^{\prime}, w^{\prime}\right) \text { iff } \forall q\left[B(q) \rightarrow q\left(\mathrm{t}^{\prime}\right)\left(w^{\prime}\right)\right] \\
& \text { and }\left\langle w_{1}, t_{1}\right\rangle \leq_{O}\left\langle w_{2}, t_{2}\right\rangle \text { iff } \forall q\left[O(q) \wedge q\left(t_{1}\right)\left(w_{1}\right) \rightarrow q\left(t_{2}\right)\left(w_{2}\right)\right] .
\end{aligned}
$$

Look again at how temporal dependence works in this analysis. The evaluated logical form (37) is a sports math reading exactly if $g(1)=B_{\mathrm{sm}}$ and $g(2)=O_{\mathrm{sm}}$. Since $g(1)$ has an intensional type $i w(i w t) t$ it gets applied to the local time and world indices of evaluation. ${ }^{16}$ Then $B$ in (36) is $B_{\mathrm{sm}}\left(t^{\prime}\right)(w)$, where $\left\langle t^{\prime}, w\right\rangle$ is week 11 in a doxastic alternative $\langle t, w\rangle$ for John. Similarly for the ordering-source function $g(2)$. As long as the premise functions are time dependent, the denotation of the phrase headed by the modal 
can be time dependent too. The sports-math modal base function premise function $B_{\mathrm{sm}}$ is time dependent, because $B_{\mathrm{sm}}(t)(w)$ has information about a monotonically increasing set of game results as $t$ increases. In fact, if $t<t^{\prime}$ then $B_{\mathrm{sm}}(t)(w) \subseteq B_{\mathrm{sm}}\left(t^{\prime}\right)(w)$, and therefore $\bigcap B_{\mathrm{sm}}\left(t^{\prime}\right)(w)$ is a subset of $\cap B_{\mathrm{sm}}(t)(w)$. So as time passes, the domain of quantification shrinks. This is similar to what happens in the branching-time metaphysical analysis.

[John believes that

[have [[in week 11] [[[might 1] 2] [Buffalo reach the playoffs ]]]] $]^{g, t, w}$

Really, also the metaphysical analysis should be couched in the general account of the compositional semantics of modals. It is easy enough to do this. We choose a modal base function $B_{\text {met }}$ which maps a time and world to a set of propositions whose intersection is the set of metaphysical alternatives to the world at the time. (38) does it with a modal base function whose value is a unit set. If we combine this with a trivial ordering source, then Condoravdi's analysis is reconstructed in the general scheme of interpretation. ${ }^{17}$

$$
B_{\text {met }}=\lambda t \lambda w \lambda p[p=\mathrm{M}(t, w)]
$$

The way that I have adopted for capturing temporal and intensional sensitivity for counterfactual readings applies to other readings of modals, such as a circumstantialdeontic reading of (39). This sentence conveys information not about the actual regulations and actual circumstances, but about what John believed the state of New Zealand case law and the circumstances to have been. For instance, it is relevant whether he believes that Deer 432 stripped the bark from the sapling.

(39) John believes deer 432 may have been personally financially responsible for the costs of the damage to a sapling.

All of this indicates that the temporal and intensional interactions that are observed for counterfactual modals are formally the same as the temporal and intensional interactions that are seen for most modals. ${ }^{18}$ Both the metaphysical analysis proposed by Mondadori and Condoravdi and the analysis advocated here fit into a general scheme of interpretation that covers these interactions. So while the temporal interactions do fall out nicely in the metaphysical analysis, they don't favor or disfavor that analysis. They are the result of the general compositional sensitivity of modals.

It is also notable that circumstantial modality mixes with legal modality in the deer examples in the same way that that circumstantial modality mixes with physical modality in the tree examples. So, assuming the general two-parameter theory of the semantics of modality and the way it is applied in other cases, if speakers use a rule-of-thumb physical modality represented in the ordering source, it is predictable that it should mix with a circumstantial modal base to produce a temporally sensitive circumstantial reading.

How should the anything-is-possible intuitions mentioned in Section 2 be represented in the articulated theory? The wife's argument in the tree scenario uses a circumstantial modal base that captures certain facts about the physical situation of the tree at the past reference time, including the orientation of the rot inside. This is combined with an ordering source that captures a rule-of-thumb story about how trees move. The wife would agree, let us assume, that it was in principle possible for a mighty gust of wind to push the tree onto the orchids. Is this compatible with (40) being true relative to the 
modal parameters that the wife is assuming? Confronted with the possibility of the mighty gust, the wife could reply that although anything is possible, she meant that the tree could not have fallen on the orchids in a normal course of events. The notion of a normal course of events can be encoded in an ordering source that captures a rule-ofthumb account of tree motion. For her sentence to be true, there should (roughly) be no maximal way of satisfying the ordering source that absolutely satisfies the modal base and has the tree falling on the orchids. This is compatible with the tree falling on the orchids in a world that satisfies the modal base, but not a maximal part of the ordering source. Worlds where the tree falls on the orchids are possible according to the modal base, but are not normal according to the ordering source.

The tree could not have fallen on the orchids. The rot was on the other side.

This account using the ordering source is not my account of the truth of the husband's sentence. The husband does not simply mean that the tree could have fallen on the orchids in freak contingencies, because this is very weak. He means that in view of the answers to the questions about the circumstances that it is relevant to ask, and a theory of tree motion that it is reasonable to assume, the tree could just as well have fallen on the orchids. $^{19}$

\section{A time dependence puzzle}

According to the analysis from the previous section, if sentence (41) is true, it is because the intended circumstantial premise function maps the base world $w_{0}$ and the time 12:00 to a set of propositions that is consistent with John finishing the race, given also the theory of runner performance that is captured by the intended ordering source function. If we are talking about possibility in view of the physical state of John's body, then the circumstantial premises might be that the energy level in John's muscles is high, his blood sugar is high, etc. So the circumstantial premise set is along the lines of what is described at the top in (41)c. Let's assume that each premise is true at world $\mathrm{w}_{0}$ and time $t_{12: 00}$, and that the set of premises is consistent with John subsequently finishing the race (and with a maximal consistent part of the ordering source). Then there is an alternative $\left\langle t_{1}, w_{1}\right\rangle$ that is in the intersection of $B\left(\mathrm{t}_{12: 00}\right)\left(\mathrm{w}_{0},\right)$ and a time $t_{2}$ following $t_{1}$, such that in world $w_{1}$ John finishes at a time $t_{2}$. For (41) to be true, the premise set $B\left(\mathrm{t}_{12: 30}\right)\left(\mathrm{w}_{0}\right)$ should exclude John finishing (in a world consistent with a maximal consistent part of the ordering source). Assume that this is because physiological parameters have changed in the way exemplified at the bottom in (41)c.

a. At noon, John still might have finished the race.

b. But at 12:30, he could not have finished the race.

c. $B\left(\mathrm{t}_{12: 00}\right)\left(\mathrm{w}_{0}\right)=\{\ldots$, the ATP level in John's leg muscles is $70 \%$,

John's blood sugar level is $81 \%, \ldots\}$

$B\left(\mathrm{t}_{12: 30}\right)\left(\mathrm{w}_{0}\right)=\{\ldots$, the ATP level in John's leg muscles is $20 \%$, John's blood sugar level is $19 \%, \ldots$ \} 
(42) presents a puzzle by describing a function $B^{\prime}$ which maps $w_{0}$ and $t_{12: 30}$ to timeshifted versions of the premises at $w_{0}$ and $t_{12: 00}$. According to $B^{\prime}\left(t_{12: 30}\right)\left(w_{0}\right)$ the energy level in John's legs was high half an hour earlier, John had high blood sugar levels half an hour earlier, and so forth. ${ }^{20}$ Since each of the original premises was true in $w_{0}$ at 12:00, the new premises are true in $w_{0}$ at 12:30. So those are facts about $w_{0}$ at $t_{12: 30}$. Assume that all of the premises are time-shifted in this way. Then each element of $B^{\prime}\left(t_{12: 30}\right)\left(w_{0}\right)$ is a fact about $w_{0}$ at $t_{12: 30}$. So by formal criteria, $B^{\prime}$ is a circumstantial premise function.

$B^{\prime}\left(\mathrm{w}_{0}, \mathrm{t}_{12: 30}\right)=\{\ldots$, the ATP level in John's leg muscles was $70 \%$ half an hour earlier, John was confident half an hour earlier, ... $\}$

Remember that $\left\langle t_{1}, w_{1}\right\rangle$ is an alternative to $\left\langle t_{12: 00, w_{0}}\right\rangle$ where John subsequently finishes the race. Because of the correspondence between $B\left(t_{12: 00}\right)\left(w_{0}\right)$ and $B^{\prime}\left(t_{12: 30}\right)\left(w_{0}\right)$, the pair $\left\langle t_{1}+30 \mathrm{~min}, w_{1}\right\rangle$ is an element of the intersection of $B^{\prime}\left(\mathrm{t}_{12: 30}\right)\left(\mathrm{w}_{0}\right)$. Let's make the additional assumption that, because of the length of the race, the time in $w_{1}$ where John finishes would have to be more than 30 minutes after $t_{1}$. In that case, the pair $\left\langle t_{1}+30 \mathrm{~min}, w_{1}\right\rangle$ is a witness for the truth of (43) relative to $B^{\prime}$. This gives the unwanted result that sentence $(41) \mathrm{b}$ is false. Intuitively, it seems false in the scenario where John has no energy in his muscles at 12:30.

At 12:30, he could have finished the race.

The problem must be that $B$ ' is an 'unnatural' circumstantial premise function, which should be excluded somehow. Notice the way how odd (44) sounds.

At 12:30, in view of his physical condition half an hour before, he could have finished the race.

The need for constraint on premise functions is not very surprising, because in general, only certain kinds of premise functions are used in evaluating natural language modals. (45) describes an unnatural premise function for a deontic modal, which picks out the zoning regulations for the town of Ithaca at 12:00, and college regulations at $12: 30$. Suppose that the college regulations do not allow open book exams, but that open book exams are consistent with the zoning regulations. With this crazy premise function, (43) is true, not because any regulations have changed, but because the premise function has an odd time-dependent conditional description similar to the predicate 'grue' of Goodman (1955). It seems very difficult to understand (43) as true in the described circumstances. $^{21}$ This means that the premise function $O$ must be excluded somehow, either in the semantic or the pragmatic component.

$$
\begin{gathered}
O\left(t_{12: 00}\right)\left(w_{0}\right)=\text { the set of zoning regulations of the Town of Ithaca in } \mathrm{w}_{0} \text { at } \mathrm{t}_{12: 00} \\
O\left(t_{12: 30}\right)\left(w_{0}\right)=\text { the set of regulations for giving final exams of the Cornell College of } \\
\text { Arts and Sciences in } \mathrm{w}_{0} \text { at } \mathrm{t}_{12: 30}
\end{gathered}
$$

(46) At noon, I could still have given an open book exam. But by 12:30, I could not have given an open book exam.

These problems are symptoms of the modal semantics I am working having so much freedom in the choice of premise functions. From what I have said so far, anything of the 
right type counts as a premise function. The examples above indicate that the space of premise functions has to be restricted, or more broadly, mechanisms have to be identified by which speakers and hearers are able to agree on rather specific premise functions. For circumstantial modality, one possibility is to constrain what counts as a fact about a world and time. If John having low blood sugar in $w_{0}$ at $t_{12: 30}$ counts a fact about $w_{0}$ and

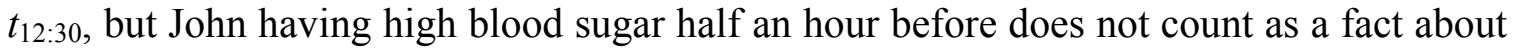
$w_{0}$ and $t_{12: 30}$, then the range of $B$ ' is not a set of facts. This offers a principled way of excluding it. $^{22}$

Here is another approach. If an expert on road races asserted the sentences in (41), I would take her to relying on some kind of rule-of-thumb, experience-based theory about how road races turn out given the physical state of runners. I would also assume that she is using a theory and corresponding properties of the circumstances that have better predictive power than competitors. It is clear that predictions about race success that are based on the physical state of the runner at the reference time are more reliable than predictions that are based on the physical state of the runner half an hour before. If we are talking about the possibilities at 12:30 of John finishing, his physical state at 12:00 is of some relevance, but his physical state at 12:30 is much more relevant. Any degree of strength in his legs at 12:00 is trumped by his legs being weak at 12:30. On this hypothethis, $B$ ' should be excluded because the theory of race success that goes with it obviously has less predictive power than one based on $B$.

\section{Summary}

Section 2 argued that the modality in counterfactual modals was not always metaphysical, because there are examples and scenarios where facts about the base world and reference time either absolutely exclude the outcome described by the complement of the modal, or exclude the outcome occurring in a normal course of events. The problem for the metaphysical analysis is that these facts are also facts about metaphysical alternatives. The examples also showed that the truth value of counterfactual modals varies according to what facts about the base world one "pays attention to". The modality in counterfactual modals is not epistemic, because in some cases there are no agents who have the information that supplies the domain of quantification for the modal.

Section 3 proposed an analysis using circumstantial modal bases, which capture a context-dependent set of facts about the base world and reference time. This permits some facts of about the base world to not be facts about the alternatives described by the modal base. Context- or purpose-dependent variation in truth value was captured straightforwardly, by assuming different circumstantial modal bases. The analysis was formulated in a version of the premise semantics for modality that used time and worlddependent premise sets. This accounts for the temporal dependence and the similar intensional dependence of counterfactual modality, in a way that is formally identical to the temporal and intensional dependence seen with most modals.

The final version of the theory followed Kratzer (1991) in using two implicit functions whose values are premise sets, the modal base and a separate ordering source. In many of the core examples of counterfactual modality, the ordering source encodes a rule-ofthumb physical theory, which combines with a circumstantial modal base. 
A pocket version of the analysis is that "the tree could have fallen on the orchids" is true if and only if the tree falling on the orchids is consistent with the answers to the questions about the circumstances that it is relevant to ask, and with a consistent reading of a rule-of-thumb theory of tree motion that it is relevant to assume.

\section{Acknowledgements}

Versions of this paper were presented at Tübingen in June 2006, Frankfurt in June 2007, ZAS Berlin in June 2007, the $16^{\text {th }}$ Amsterdam Colloquium in December 2007, at Cornell in February 2008, and at JNU, New Delhi in January 2011. The Amsterdam paper appeared as Abusch (2007). I am grateful to the audiences on those occasions for their reactions. Thanks to Anton Benz, Wylie Breckenridge, Jiwon Yun, Manfred Krifka, Angelika Kratzer, Manfred Kupffer, Cécile Meier, Magdalena Schwager, Arnim von Stechow, Doris Penka, and Ede Zimmermann for their reactions. The final version benefitted greatly from the comments of a NALS reviewer. Special thanks to Mats Rooth for lots of discussion of various versions of this research.

\section{Endnotes}

1. Whatever the implementation, the evidence for this scope relation seems good. Condoravdi points out that in the German example (i), the have form hätte is in the V2 position, so that it is syntactically above the modal können. As pointed out in Yun (2006), Korean also has the temporal and modal operators in a morpho-syntactic order isomorphic to the logical one. Examples (ii) and (iii) are quoted from Yun.

(i) Er hätte noch gewinnen kőnnen.

(ii) ku-ka iki-l swu-to iss-ess-ta. kulenaku-nun kyelkwuk ci-ess-ta

he win might PAST but he eventually lost PAST

'he might have won, but he eventually lost'

Syntactic and semantic scope of operators: ... win) might) PAST).

(iii) ku-ka imi iki-ess-ul swu iss-ta

he already win PAST might

'he might already have won' (epistemic).

Syntactic and semantic scope of operators: ... win) PAST) might).

An obvious possibility about English is that since modals do not have participial forms, a syntax-semantics mismatch is forced, with a semantically subordinate modal surfacing in the syntactically superior position. In Swedish however, the counterpart of can does have a participial variant, as shown in (iv). Nevertheless counterfactual havemodal combinations surface with the modal in the V2 position, as shown in (v). Notice however that the modal kunde in (v) is a past tense one, so that the temporal operator scoping over the modal could be the past tense. Stowell (2004) makes a similar proposal for English.

(iv) Jag har inte kunnat tänka på det.

I have-pres not can-supine think-inf on it 
'I haven't been able to think about it.'

(v) Jag kunde ha dödats

I can-past have-inf kill-supine-passive

'I could have been killed.'

The German order is apparently also possible in Swedish, though perhaps only rarely, marginally, or in restricted morpho-syntactic contexts. (vi) and (vii) are simplified from examples found online by Mats Rooth.

(vi) Om bomben hade sprängts, hade människor kunnat

if bomb-def have-pst detonate-supine-pass have-pst people-pl can-pst

dödats, säger polisen.

kill-supine-pass say-pres police-def

'If the bomb had been detonated, people could have been killed, say the police.'

(vii) Människor hade kunnat dödats i den här katastrofen.

people have-pst can-supine kill-supine-pass in the here catastrophe.

'People could have been killed in this catastrophe.'

2. Related proposals are made in Abusch (1998) and von Stechow (2003). In the former, future-oriented modal have in their scope an operator which substitutes an interval $(n, \infty)$ for evaluation time parameter $n$, with the effect of stretching the evaluation time forward. This is used to analyze interactions between past tense and future-oriented modals.

3. See Thomason (1984) for a formal development.

4. In (7b) the wife's sentence uses could rather than might because in a version with might, the negation can not scope over the modal. But as I understand it, the two modal are equivalent in this context. Some speakers have told me that other examples sound more natural with could in place of might. Such speakers should make the substitution.

5. The "merging" of the belief attitude with a doxastic existential modal could result from the modal-logic identity $\square \backslash p \equiv \square p$, or from the mechanism proposed in Hacquard (2010).

6. That the justification in (16) uses a counterfactual suggests a logical link between the simple modal sentences analyzed in this paper, and counterfactuals with if. The semantics for simple counterfactual modals stated in Section 3 uses premise semantics, and this semantics is used as a semantics for counterfactuals with if by Veltman (1976) and Kratzer (1981). So it should be possible to check the validity of the argument formally. I conjecture that this would show that the two speakers of (15) and (16) could not be assuming the same modal base and ordering source, because relative to an ordering source that includes the information that Ljubojević never changes strategy, (15) would be false. This would sustain the claim that these examples involve a change in contextual parameters. See the end of Section 3 and footnote 19 for my position on the similarity between (15)-(16) and Lewis-Sobel sequences of counterfactuals.

7. Thanks to a NALS reviewer for bringing up world-time lines with discontinuities. 
8. The Buffalo and Shredder examples also involve determinism, because for the counterexamples to work, there must be some facts about the base world that absolutely exclude Buffalo winning, or Shredder 9 defeating Shredder 10. While this is a kind of determinism, it is a different because it does not require worlds being deterministic.

9. As I understand things, the court considered the assertion of impossibility in (19) correct in the intended reading, which I have hypothesized is a circumstantial reading. The court rejected the argument as a whole as irrelevant, given the established legal interpretation of the notion of attempted crime. I don't know what the court meant with "legally" in "legally or factually impossible".

10. See Veltman (1976), Kratzer (1981,1991), and Lewis (1981). The main application of premise semantics is to counterfactuals with if. These are not being analyzed here. However, as mentioned in footnote 6, there are logical links between bare counterfactual modals, and counterfactuals with if. In many cases, when a sentence like (i) with a counterfactual modal is true, there is a corresponding true counterfactual with if like (ii). Sentence (iii) is an if-counterfactual for the trees scenario.

(i) In week 11 of the football season, mathematically, Buffalo could still have reached the playoffs.

(ii) If Detroit had defeated Miami in week 12, Washington had defeated Cincinnati in Week 12 by at least 21 points, ..., and Arizona had defeated San Diego by at least 14 points in Week 17, then Buffalo would have reached the playoffs.

(iii) If the internal rot had been on the opposite side, the tree would/might have fallen on the office.

11. Putting aside times, in the VP-topicalization example (31), the index 2 has to have an intensional type set, rather than an extensional type et, in order for the semantics to refer to individuals that are asleep at Mary's doxastic alternatives, rather than individuals that are asleep in the base world. A local interpretation with type et is obtained with the "intensional traces and pronouns rule" presented by Mats Rooth in class lectures at Cornell:

(i) If $\alpha$ is an empty category or pronoun with index $\langle n, s a\rangle$ then $\llbracket \alpha \rrbracket^{g, w}=g(\langle n, s a\rangle)(w)$.

Let the VP trace in (31) have index $\langle 2$,set $\rangle$. Then $\llbracket\left[\mathrm{vP}_{\mathrm{t}}\right]_{(2, \text { set })} \rrbracket^{g, w}=g(\langle 2$, set $\rangle)(w)$, with type et and world parameter of evaluation plugged in as the argument of the interpretation of the variable. In my system times are separated from worlds:

(ii) If $\alpha$ is an empty category or pronoun with index $\langle n, i w a\rangle$, then $\llbracket \alpha \rrbracket^{g, t, w}=$ $g(\langle n, i w a\rangle)(t)(w)$.

Let the argument of might in (30) have index $\langle 1, i w(i w t) t\rangle$, and let $g(\langle 1, i w(i w t) t\rangle)=$ $\operatorname{Pr}_{\mathrm{sm}}$. Then the interpretation of the argument of might relative to $g, t$, and $w$ is $g(\langle 1, i w(i w t) t\rangle)(t)(w)=\operatorname{Pr}_{\mathrm{sm}}(t)(w)$, with the premise function applied to the time and world parameters of evaluation.

The treatment in von Fintel and Heim (ms.), Chapter 3, of outside intensionality interacting with modals plugs in the world parameter of evaluation as an argument of the modal parameter in the lexical entry of the modal. In their rule (iii), the implicit 
argument of the modal $R$, (which is a function from worlds to propositions), is applied to the world parameter in the term $R(v)$.

(iii) $\llbracket$ must $\rrbracket^{g, v}=\lambda R_{s s t} \lambda q_{s t} \forall u[R(v)(u) \rightarrow q(u)]$

12. Kratzer's version of the deer example did not have reference to a specific deer and damage incident. Adding it brings out that the legal modality can mix with a circumstantial modal base.

13. The subset of the ordering source is to be maximized while preserving consistency with the modal base. Let $G$ be the family of subsets of the union of the modal base and the ordering source that contain the modal base and are consistent (have a non-empty intersection). Then an existential modal is true (relative to the modal base and ordering source) if the complement of the modal is consistent with some element of $G$ that is maximal in the subset ordering on $\mathcal{G}$. (An element of $\mathcal{G}$ is a set of propositions. In maximizing the element, as many propositional premises as possible are added while preserving consistency.)

14. The framework with two premise sets creates flexibility in where the husband's modal parameters could differ from the wife's. The difference could be located in the modal base, the ordering source, or both.

15. This is a version of the definition of human possibility from Kratzer (1981b) that builds in a future operator. Often a more intuitive term is "good possibility" or "easy possibility", since the corresponding adverbs can be inserted:

(i) The tree could easily have fallen on the orchids.

It may be advisable to tread the futurity separately from the modality, or to condition the futurity on aspectual type. This would allow simultaneous readings such as this one to be treated. John is an expert petroleum geologist and investor. In 2003, he finds a ranch property in Ecuador and analyzes its geology very carefully. He applies best-practice methodology for petroleum prospecting. He decides the ranch has a good probability of containing a large oil reserve, and on December 1, 2003 buys the property together with a partner. Unfortunately, expensive drilling establishes that there is only worthless salty water under the ranch. The partner's opinion on Dec. 18, 2007:

(ii) We bought a ranch which (when we bought it) might well have contained a significant oil reserve. But unfortunately there is no oil on this ranch. Let's sell it and move on to the next project.

I assume that in this example, the modal does not build in futurity, and that there should not be a future operator in the immediate scope of the modal. The ice cream example in Von Fintel and Gillies (2008) seems similar. Sophie was looking for some ice cream and opened the freezer. None is there. Asked why she opened the freezer, she replied:

(iii) There might have been ice cream in the freezer. 
Maybe these are epistemic readings (as von Fintel and Gillies' discussion implies), but they could also involve a circumstantial modal base, mixed for the ranch example with an ordering source capturing best-practice prospecting methodology.

16. This is how the dependence on $w$ and $t$ comes about in the account explained in footnote 11. [might $\rrbracket^{g, t, w}$ as defined in (36) has no dependence on $w$ or $t$.

17. This definition assumes that $\mathrm{M}(t, w)$ has type $i w t$. In definition (3)d it has type $w t$, and that definition uses identification of the time $t$ across worlds.

18. I say "most" to allow for modals with special scope or deictic properties.

19. And on my account, combining the husband's and wife's arguments into an argument with the conclusion $p \wedge \neg p$ is a fallacy of equivocation in the shift from the husband's modal base function to the wife's. This agrees with the intuition about the slyness of the wife's argument. Lewis-Sobel sequences such as (i) and (ii) are superficially similar to the tree examples, but Lewis maintains that they do not involve a shift in implicit parameters (Lewis 1973:10).

(i) If I (or you, or anyone else) walked on the lawn, no harm at all would come of it; but if everyone did that, the lawn would be ruined.

(ii) If the USA threw its weapons into the sea, there would be war; but if the USA and the other nuclear powers all threw their weapons into the sea tomorrow there would be peace $(. .$.$) .$

The wife's reaction to the possibility of the mighty gust as I analyze it reflects Lewis-Sobel thinking, but that the disagreement between the wife and the husband is different.

20. To complete the example one needs a complete definition of $B^{\prime} . B^{\prime}$ is a systematically time-shifted version of $\mathrm{B}$, with $B^{\prime}(t)(w)=B(t-30 \mathrm{~min})(w)$.

21. Perhaps not impossible though. Suppose the value of the ordering function is the set of regulations that we are disposed to pay attention to at $t$. At 12:00, we are of the opinion that University regulations can freely be ignored. By 12:30 we have started paying attention to them. So we can no longer give an open book exam, because we became disposed to pay attention to University regulations.

22. This option is suggestive of the proposal in Kratzer (2002) that "propositional facts" are relevant to the evaluation of counterfactuals.

\section{References}

Abusch, Dorit. 1998. Generalizing tense semantics for future contexts. In Events and Grammar, ed. Susan Rothstein, 13-33. Dordrecht: Kluwer.

Abusch, Dorit. 2004. On the temporal composition of infinitives. In The Syntax of Time, eds. Jacqueline Gueron and Jacqueline Lecarme, 27-54. Cambridge: MIT Press. 
Abusch, Dorit. 2007. Temporal and circumstantial dependence in counterfactual modals. Proceedings of the Sixteenth Amsterdam Colloquium, 37-42. ILLC, University of Amsterdam.

Bach, Emmon. 1986. Natural Language Metaphysics. In Logic, Methodology, and Philosophy of Science VII, eds. R. Barcan Marcus, G.J.W. Dorn and P. Weingartner, 573-595. Amsterdam: North Holland.

Condoravdi, Cleo. 2002. Temporal interpretation of modals: modals for the present and for the past. In The Construction of Meaning, eds David Beaver, Luis D. Cassillas Maritinez, Brandy Z. Clark and Stephan Kaufmann, 00-000. Stanford: CSLI.

von Fintel, Kai, and Anthony S. Gillies. 2008. CIA leaks. Philosophical Review, 117(1), 77.

von Fintel, Kai, and Irene Heim. Manuscript. Intensional Semantics. Lecture notes, MIT.

Goodman, Nelson. 1955. Fact, Fiction, and Forecast. Cambridge, MA: Harvard University Press.

Hacquard, Valentine. 2010. On the event relativity of modal auxiliaries. Natural Language Semantics 18.1.

Kansas Supreme Court. 2001. Judgment in State vs. Jones, State of Kansas, Appellee, v. Russell J. Jones, Appellant, No. 84,810.

Karttunen, Lauri. 1977. Syntax and semantics of questions. Linguistics and Philosophy 1(1):3-44.

Kratzer, Angelika. 1977. What 'must' and 'can' must and can mean. Linguistics and Philosophy, 1(3), 337-355.

Kratzer, Angelika. 1981a. Partition and revision: the semantics of counterfactuals. Journal of Philosophical Logic 10: 242-258.

Kratzer, Angelika. 1981b. The notional category of modality. In Words, Worlds, and Contexts. New Approaches in Word Semantics, eds. H.J. Eikmeyer and H. Rieser, 3874. Berlin: de Gruyter.

Kratzer, Angelika. 1991. Modality. In Semantics: An international handbook of Contemporary Research, Arnim von Stechow and Dieter Wunderlich (eds.), 639-650. Berlin:de Gruyter.

Kratzer, Angelika. 2002. Facts: particulars or information units? Linguistics and Philosophy 25(5-6):655-670.

Lewis, David. 1973. Counterfactuals. Oxford: Blackwell.

Lewis, David. 1981. Ordering semantics and premise semantics for counterfactuals. Journal of Philosophical Logic, 10(2), 217-234.

Mondadori, Fabrizio. 1978. Remarks on tense and mood: the perfect future. In Studies in Formal Semantics: Intensionality, Temporality, Negation, eds. Franz Guenthner and Christian Rohrer, 223-248. Amsterdam: North Holland.

Montague, Richard. 1973. The proper treatment of quantification in ordinary English. Approaches to Natural Language, 49, 221-242.

von Stechow, Arnim. 2003. Feature deletion under semantic binding: tense, person, and mood under verbal quantifiers. NELS 33.

Stowell, Tim. 2004. Tense and modals. In The Syntax of Time, eds. Jacqueline Gueron and Jacqueline Lecarme, 621-636. Cambridge: MIT Press. 
Thomason, Richmond H. 1984. Combinations of tense and modality. In Handbook of Philosophical Logic, 2, 135-165.

Veltman, Frank. 1976. Prejudices, presuppositions, and the theory of counterfactuals. In Proceedings of the $1^{\text {st }}$ Amsterdam Colloquium, eds J. Groenendijk \& M. Stokhof, 248281. University of Amsterdam.

Yun, Jiwon. 2006. Tense, modals, and counterfactuality. Manuscript, Dept. of Linguistics, Cornell University. 